\title{
Efeito da temperatura ambiente sobre o desempenho e as características de carcaça de frangos de corte dos 22 aos 42 dias $^{1}$
}

\author{
Gisele Andrade de Oliveira ${ }^{2}$, Rita Flávia Miranda de Oliveira ${ }^{3}$, Juarez Lopes Donzele ${ }^{3}$, Paulo \\ Roberto Cecon ${ }^{4}$, Roberta Gomes Marçal Vieira Vaz ${ }^{2}$, Uislei Antonio Dias Orlando ${ }^{5}$ \\ 1 Parte da tese de Mestrado da primeira autora. Projeto financiado pela FAPEMIG. \\ 2 Universidade Estadual do Sudoeste da Bahia. \\ ${ }^{3}$ Departamento de Zootecnia - UFV. \\ 4 Departamento de Informática - UFV. \\ 5 Perdigão.
}

RESUMO - Este estudo foi realizado para avaliar o efeito da temperatura ambiente sobre o desempenho e as características de carcaça de frangos de corte no período de 22 a 42 dias de idade. Foram utilizados 336 frangos machos da linhagem Avian Farm (peso médio inicial de $624 \mathrm{~g}$ ) distribuídos em delineamento experimental inteiramente casualizado, com quatro tratamentos (temperaturas ambientais $-16,20,25$ e $32^{\circ} \mathrm{C}$, o primeiro constituído de 12 repetições e os demais, de 24 repetições), todos com quatro aves por unidade experimental. Os tratamentos influenciaram o ganho de peso e os consumos de ração e energia metabolizável, que aumentaram de forma quadrática até as temperaturas estimadas de 24,4; 19,$1 ;$ e $19,1^{\circ} \mathrm{C}$, respectivamente. A conversão alimentar também variou de forma quadrática, melhorando até a temperatura estimada de $26,3^{\circ} \mathrm{C}$. Os tratamentos influenciaram os rendimentos de carcaça e peito, que variaram de forma linear com o aumento da temperatura de 16 até $32^{\circ} \mathrm{C}$. O rendimento de coxa sofreu efeito quadrático, aumentando até a temperatura estimada de $19,4^{\circ} \mathrm{C}$. Os pesos absolutos de coração, fígado e moela e os pesos relativos de coração e moela também foram influenciados pelas temperaturas, sendo maiores em temperaturas mais baixas $\left(16^{\circ} \mathrm{C}\right)$ e menores nas mais elevadas $\left(32^{\circ} \mathrm{C}\right)$. $\mathrm{O}$ peso relativo de fígado aumentou de forma linear com a elevação da temperatura de 16 a $32^{\circ} \mathrm{C}$. No entanto, os pesos absoluto e relativo de proventrículo não foram influenciados pelos tratamentos. Os melhores resultados de ganho de peso e dos pesos absolutos de carcaça, peito e coxa foram obtidos quando nas aves criadas em ambientes com temperatura de 24 a $26,3^{\circ} \mathrm{C}$. Temperaturas ambientais abaixo ou acima destes valores influenciam negativamente o ganho de peso e os pesos absolutos de carcaça, peito e coxa.

Palavras-chave: carcaça, desempenho, frango de corte, temperatura

\section{Effect of environmental temperature on performance and carcass characteristics of broilers from 22 to 42 days old}

\begin{abstract}
This study was conducted to evaluate the effect of environmental temperature on performance and carcass characteristics of male broilers in the period from 22 to 42 days old. Three hundred and thirty-six male Avian Farm broilers, averaging $624 \mathrm{~g}$ were allotted to a randomized experimental design, with four treatments (temperatures of 16, 20, 25 and $32^{\circ} \mathrm{C}$ ). The treatment 1 consisted of 12 replicates and the others of 24 replicates, all with four birds per experimental unity. The treatments affected weight gain, feed intake and metabolizable energy intake that quadractly increased until the estimated temperatures of $24.4,19.1$ and $19.1^{\circ} \mathrm{C}$, respectively. Feed:gain ratio also changed in a quadratic way, increasing until the estimated temperature of $26.3^{\circ} \mathrm{C}$. The treatments influenced the carcass and breast yield that changed in a linear way as the temperature increased from 16 to $32^{\circ} \mathrm{C}$. Thigh yield changed in a quadratic way, increasing until the estimated temperature of $19.4^{\circ} \mathrm{C}$. The absolute weights of heart, kidney and gizzard and the relative weights of heart and gizzard were affected by the environmental temperatures and were higher in cold environment $\left(16^{\circ} \mathrm{C}\right)$ and smaller in the hot environment $\left(32^{\circ} \mathrm{C}\right)$. The relative weight of kidney linearly increased as the temperature increase from 16 to $32^{\circ} \mathrm{C}$. However, no treatment effect on absolute and relative weights of proventriculus was observed. It was concluded that the best results of weight gain and absolute weights of carcass, breast and thigh are obtained when the birds are reared on environmental temperatures from 22.3 to $24.7^{\circ} \mathrm{C}$. Environmental temperatures bellow or above these values affect negatively weight gain and absolute weights of carcass, breast and thigh.
\end{abstract}

Key Words: broiler chicken, carcass, performance, temperature 


\section{Introdução}

A avicultura evoluiu consideravelmente nos últimos tempos e conquistou, a partir da década de 70, significativa participação na produção de proteína de origem animal e grande importância sócio-econômica para o país. A avicultura do Brasil destaca-se entre as três maiores do mundo e por ser, no setor agropecuário, a atividade com maior tecnificação e produtividade, como resultado dos avanços nas áreas de manejo, melhoramento genético, nutrição e sanidade.

Entretanto, a avicultura de corte moderna, para atingir melhores resultados econômicos e produtivos, precisa avançar não só nos aspectos genéticos, nutricionais e sanitários, mas também nos aspectos ambientais, que interferem diretamente na expressão do potencial genético, na eficiência de utilização de nutrientes e nos aspectos sanitários das aves.

O estresse causado pelo ambiente térmico influencia a produtividade dos animais por alterar sua troca de calor com o ambiente e modificar a taxa de consumo de alimentos, a taxa de ganho de peso corporal e, conseqüentemente, as exigências nutricionais (Curtis, 1983). Nesse processo, os fatores externos do ambiente (temperatura, umidade relativa, vento, radiação etc) tendem a produzir variações internas nas aves, influenciando a quantidade de energia trocada entre ave e ambiente, havendo, muitas vezes, a necessidade de ajustes fisiológicos para a ocorrência do balanço de calor (Baeta \& Souza, 1998).

A alta temperatura ambiente influencia diretamente a manutenção da homeotermia, com o conseqüente comprometimento do desempenho das aves, atribuído, principalmente, à ineficiência das aves em eliminar o excesso de calor corporal (Donkoh \& Atuahene, 1988). Entretanto, quando o animal é submetido a temperatura abaixo da região de conforto, ele destina parte da energia ingerida para gerar calor para manutenção da temperatura corporal, o que leva à redução da produtividade (McDowell, 1974).

Além do desempenho, a temperatura ambiente modifica a retenção de energia, proteína e gordura no corpo animal e provoca diversas mudanças adaptativas fisiológicas, entre elas a modificação no tamanho dos órgãos, o que também contribui para alterar a exigência nutricional das aves, visto que o gasto de energia pelos tecidos metabolicamente ativos, como fígado, intestino e rins são maiores que aquele associado à carcaça (Baldwin et al., 1980).

Conduziu-se este estudo para avaliar o efeito da temperatura ambiente sobre o desempenho, as características de carcaça e os parâmetros fisiológicos de frangos de corte machos no período de 22 aos 42 dias de idade.

\section{Material e Métodos}

O experimento foi realizado no Laboratório de Bioclimatologia Animal do Departamento de Zootecnia do Centro de Ciências Agrárias da Universidade Federal de Viçosa, em Viçosa, MG.

Foram utilizados 336 frangos de corte machos Avian Farms (peso inicial médio de 624 g) no período de 22 a 42 dias de idade. O delineamento experimental utilizado foi o inteiramente casualizado, com quatro tratamentos (temperaturas ambientais - $16,20,25$ e $32^{\circ} \mathrm{C}$, o primeiro constituído de 12 repetições e os demais, de 24 repetições), todos com quatro aves por unidade experimental.

No período inicial (1 a 21 dias de idade), as aves foram criadas em galpão convencional, sendo manejadas e alimentadas conforme descrito no manual da marca Avian Farms, e receberam ração à base de milho e farelo de soja, com $21,6 \%$ de PB e 3.000 kcal de EM. Completados os 21 dias de idade, os frangos foram pesados e transferidos para as câmaras climáticas, quando teve início o período experimental. As aves foram alojadas em baterias metálicas com piso de arame, com compartimentos de $0,85 \times 0,43 \mathrm{~m}$, providos de comedouro e bebedouro tipo calha, mantidas em salas climatizadas conforme os respectivos tratamentos.

As condições ambientais das salas (temperatura e umidade relativa do ar) foram monitoradas diariamente em dois horários ( 8 e 18h), por meio de termômetros de bulbo seco, bulbo úmido e de globo negro, mantidos no centro das salas.

O programa de luz foi o contínuo (24 horas de luz artificial) durante todo o período experimental, utilizando-se lâmpadas fluorescentes de 75 watts.

A ração utilizada (Tabela 1) contendo $20 \% \mathrm{~PB}$ e $3.150 \mathrm{kcal}$ de EM, foi formulada para satisfazer às exigências nutricionais dos frangos, conforme descrito por Rostagno et al. (1996). Durante o período experimental, as aves receberam ração e água à vontade. A água foi trocada duas vezes ao dia para evitar que aquecesse.

A partir do oitavo dia de experimento, uma vez ao dia (9h) a cada seis dias, foram tomadas as temperaturas retal e da pele em três pontos do corpo da ave por repetição. A temperatura retal foi obtida utilizando-se termômetro digital, introduzindo-se a sonda no reto das aves durante $\pm 1 \mathrm{~min}$ e $15 \mathrm{seg}$. A temperatura da pele foi medida por meio de termômetro de infravermelho de ponto, direcionado contra a pele da ave (na crista, no peito e na perna).

As aves foram pesadas no início e ao final do período experimental, para determinação do ganho de peso. O consumo de ração foi calculado considerando-se a ração 
Tabela 1 - Composições centesimal e calculada da ração experimental

Table 1 - Ingredient and calculated compositions of the experimental diet

\begin{tabular}{lc}
\hline $\begin{array}{l}\text { Ingrediente } \\
\text { Ingredient }\end{array}$ & $\begin{array}{c}\text { Quantidade } \\
\text { Amount }\end{array}$ \\
\hline Milho (Corn) & 55,266 \\
Farelo de soja (Soybean meal) & 36,620 \\
Fosfato bicálcico (Dicalcium phosphate) & 1,500 \\
Calcário (Limestone) & 1,000 \\
BHT (Antioxidant) & 0,010 \\
Cloreto de colina (Choline chloride) & 0,060 \\
Sal comum (Salt) & 0,329 \\
Mistura mineral ${ }^{1}$ (Mineral mix) & 0,050 \\
Mistura vitamínica ${ }^{2}$ (Vitamin mix) & 0,100 \\
DL-metionina (DL-methionine) & 0,185 \\
Coxistac* & 0,050 \\
Óleo vegetal (Vegetal oil) $_{\text {Virginiamicina (Virginiamicin) }}$ & 4,780 \\
\hline
\end{tabular}

Composição calculada

Calculated composition

\begin{tabular}{|c|c|}
\hline Energia metabolizável (kcal/kg) & 3.150 \\
\hline \multicolumn{2}{|l|}{ (Metabolizable energy) } \\
\hline Proteína bruta (Crude protein) (\%) & 20,00 \\
\hline Cálcio (Calcium) (\%) & 0,872 \\
\hline Gósforo disponível (Available phosphorus) (\%) & 0,382 \\
\hline Sódio (Sodium) (\%) & 0,176 \\
\hline Lisina (Lysine) $(\%)$ & 1,178 \\
\hline Metionina + Cistina (Methionine + Cystine) $(\%)$ & 0,820 \\
\hline \multicolumn{2}{|c|}{ 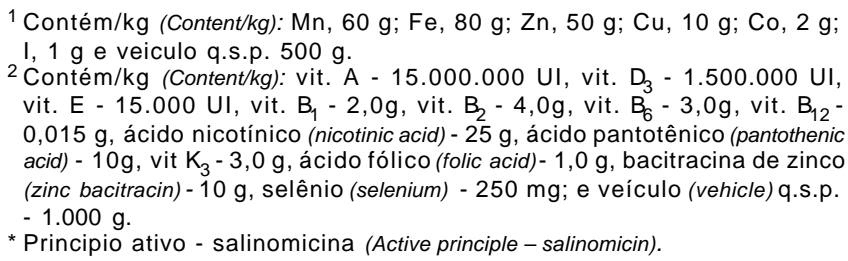 } \\
\hline
\end{tabular}

fornecida, os desperdícios e as sobras das rações nos co medouros durante o período experimental. Posteriormente, calculou-se a conversão alimentar.

No final do período experimental (420 dia), após 12 horas de jejum, foram abatidas duas aves por boxe, por meio de deslocamento cervical, selecionadas conforme a média do peso de cada boxe, ou seja, aves com peso $10 \%$ acima ou abaixo do peso médio do boxe, para avaliação do rendimento de cortes nobres (coxa e peito).

$O$ rendimento de carcaça foi determinado considerando-se o peso da carcaça eviscerada em relação ao peso vivo em jejum.

Os cortes (coxa e peito) foram pesados em balanças com precisão de $1 \mathrm{~g}$ e seus rendimentos foram calculados em relação ao peso da carcaça eviscerada.

As carcaças, sem sangue, sem penas e sem vísceras, foram pesadas. Os órgãos (coração, fígado, moela e proventrículo) foram retirados, cortados longitudinalmente, pendurados à sombra para que o sangue escorresse e pesados. O intestino foi aberto em toda sua extensão e, após retirado seu conteúdo, foi lavado e, depois de escorrido o excesso de água, foi pesado.

Os pesos relativos dos órgãos foram calculados da mesma forma que o dos cortes.

Foram avaliados o ganho de peso, o consumo de ração, a conversão alimentar, o peso (g) e o rendimento (\%) das carcaças inteiras (com pés e cabeça) e dos cortes nobres (coxa e peito) e os pesos absoluto (g) e relativo (\%) das vísceras (coração, fígado, moela e proventrículo).

As análises estatísticas das variáveis desempenho (ganho de peso, conversão alimentar e consumo), rendimento de cortes nobres e pesos dos órgãos foram realizadas utilizando-se o programa SAEG - Sistema para Análises Estatísticas e Genéticas (UFV, 1997).

Os dados foram analisados por meio de análises de variância e regressão. Os modelos foram escolhidos com base na significância dos coeficientes de regressão utilizados no teste "t", a 5\% de probabilidade, no coeficiente de determinação ( $\mathrm{R}^{2}=\mathrm{S}$.Q., Regressão/S.Q. tratamento) e no fenômeno em estudo.

\section{Resultados e Discussão}

Os resultados de desempenho dos frangos de corte criados em diferentes temperaturas ambiente são apresentados na Tabela 2.

Os tratamentos influenciaram $(\mathrm{P}<0,01)$ de forma quadrática o ganho de peso (GP) das aves, que aumentou até a temperatura estimada de $24,4^{\circ} \mathrm{C}$ (Figura 1). O GP das aves mantidas a $32^{\circ} \mathrm{C}$ foi $21,3 \%$ menor que o das aves mantidas em temperatura ambiente de $25^{\circ} \mathrm{C}$. Estes resultados estão em acordo com os verificados por Cooper \& Washburn (1998), que verificaram redução de 20 a $30 \%$ no GP das aves criadas em ambiente quente $\left(32^{\circ} \mathrm{C}\right)$, em comparação ao daquelas mantidas em ambiente termoneutro $\left(21^{\circ} \mathrm{C}\right)$, e com os de Oliveira Neto (1999), que também observaram redução de $27 \%$ no GP das aves mantidas em ambiente de calor em relação àquelas mantidas em conforto térmico. Oliveira Neto et al. (2000), por sua vez, trabalhando com frangos de corte em ambientes de conforto $\left(23^{\circ} \mathrm{C}\right)$ e de calor $\left(32^{\circ} \mathrm{C}\right)$ recebendo quantidades iguais de ração, constataram diminuição de $16 \%$ no crescimento das aves com o aumento da temperatura ambiente.

A piora de $19,6 \%$ observada no ganho de peso das aves mantidas em ambiente frio $\left(16^{\circ} \mathrm{C}\right)$, em relação àquelas em ambiente termoneutro $\left(25^{\circ} \mathrm{C}\right)$, confirma os resultados observados por Perrault \& Leeson (1992), que, em estudo com frangos de corte em ambiente frio $\left(15,5^{\circ} \mathrm{C}\right)$, também observaram diminuição de $20 \%$ no ganho de peso quando 
Tabela 2 - Desempenho de frangos de corte no período de 22 a 42 dias de idade mantidos em diferentes temperaturas ambiente

Table 2 - Results of performance of broilers from 22 to 42 days old on different environmental temperatures

\begin{tabular}{|c|c|c|c|c|c|}
\hline \multirow{3}{*}{$\begin{array}{l}\text { Parâmetro } \\
\text { Parameter }\end{array}$} & \multirow{2}{*}{\multicolumn{4}{|c|}{$\begin{array}{c}\text { Temperatura ambiente }\left({ }^{\circ} \mathrm{C}\right) \\
\text { Air temperature }\end{array}$}} & \multirow[b]{3}{*}{ CV (\%) } \\
\hline & & & & & \\
\hline & 16 & 20 & 25 & 32 & \\
\hline $\begin{array}{l}\text { Ganho de peso }(\mathrm{g})^{1} \\
\text { Weight gain }\end{array}$ & 1.386 & 1.588 & 1.724 & 1.357 & 7,29 \\
\hline $\begin{array}{l}\text { Consumo de ração }(\mathrm{g})^{1} \\
\text { Weight gain }\end{array}$ & 3.023 & 3.113 & 2.956 & 2.609 & 5,00 \\
\hline $\begin{array}{l}\text { Consumo de EM }(\mathrm{kcal} / \mathrm{kg})^{1} \\
\text { ME intake }\end{array}$ & 9.521 & 9.805 & 9.312 & 8.218 & 5,00 \\
\hline $\begin{array}{l}\text { Conversão alimentar }{ }^{1} \\
\text { Feed:gain ratio }\end{array}$ & 2,19 & 1,97 & 1,72 & 1,93 & 6,12 \\
\hline
\end{tabular}

Efeito quadrático $(P<0,01)$ (Quadratic effect $(P<0.01))$.

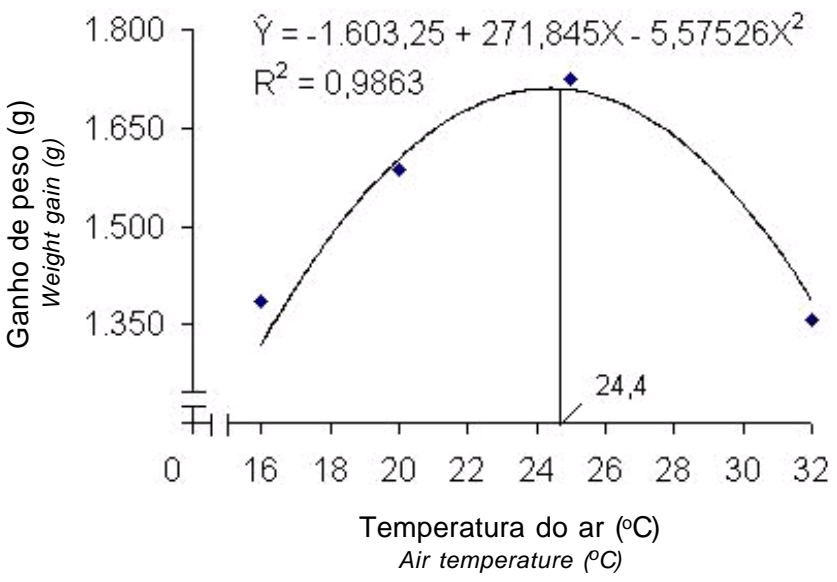

Figura 1 - Efeito da temperatura ambiente sobre o ganho de peso $(\mathrm{g})$ de frangos de corte machos no período de 22 a 42 dias de idade.

Figure 1 - Effect of environmental temperature on weight gain (g) of male broilers from 22 to 42 days old.

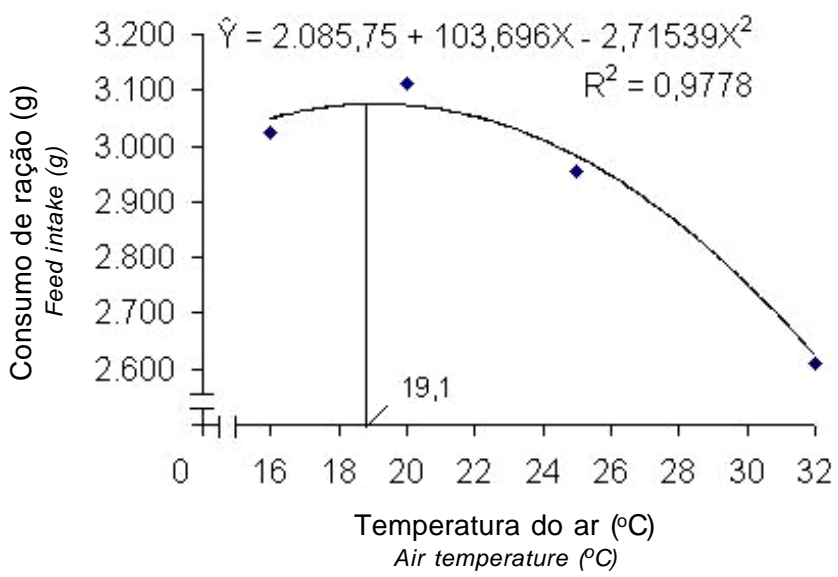

Figura 2 - Efeito da temperatura ambiente sobre o consumo de ração $(\mathrm{g})$ por frangos de corte machos no período de 22 a 42 dias de idade.

Figure 2 - Effect of environmental temperature on feed intake $(\mathrm{g})$ of male broilers from 22 to 42 days old. comparado ao daquelas criadas em ambiente termoneutro $\left(23,9^{\circ} \mathrm{C}\right)$.

A diminuição no GP ocorrida a partir da temperatura estimada de $24,4^{\circ} \mathrm{C}$ pode, em parte, ser explicada pela variação do consumo de ração (CR), que reduziu de forma quadrática $(\mathrm{P}<0,01)$ a partir da temperatura de $19,1^{\circ} \mathrm{C}$ (Figura 2). O CR das aves mantidas a $32^{\circ} \mathrm{C}$ foi $11,7 \%$ menor que o daquelas criadas a $25^{\circ} \mathrm{C}$. Estes resultados contrastam com os encontrados por Lana et al. (2000), que, avaliando diferentes programas de alimentação para frangos de corte criados sob duas temperaturas $\left(25,1\right.$ e $\left.31^{\circ} \mathrm{C}\right)$, verificaram que o GP e o CR diminuíram na mesma proporção (15\%).

A redução do consumo voluntário dos frangos de corte mantidos sob ambiente de estresse por calor em relação àqueles sob conforto térmico tem sido relatada por vários autores (Charles et al., 1981; Howlider \& Rose, 1987; Baziz et al., 1996; Cheng et al., 1997).

A diminuição do consumo de ração e do ganho de peso observada nas aves submetidas à temperatura de $32^{\circ} \mathrm{C}$ está de acordo com o relato de Baziz et al. (1996) de que aves expostas a altas temperaturas diminuem seu consumo de ração para reduzir a produção de calor metabólico e manter a homeotermia, o que resulta em decréscimo do crescimento.

O consumo de energia metabolizável (CEM) por frangos de corte variou de forma quadrática $(\mathrm{P}<0,01)$, reduzindo a partir da temperatura estimada de $19,1^{\circ} \mathrm{C}$ (Figura 3 ), com a maior queda $(11,7 \%)$ sendo observada entre as temperaturas de 25 e $32^{\circ} \mathrm{C}$. Este resultado corrobora o relato de Sell (1979) de que a relação entre consumo de energia e a temperatura ambiente parece mudar em

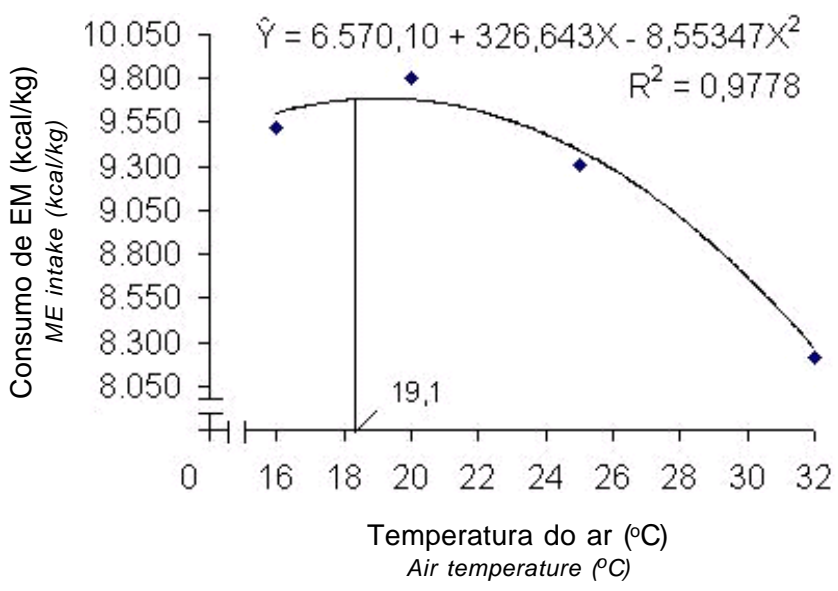

Figura 3 - Efeito da temperatura ambiente sobre o consumo de EM $(\mathrm{kcal} / \mathrm{kg})$ de frangos de corte machos no período de 22 a 42 dias de idade.

Figure 3 - Effect of environmental temperature on ME intake $(\mathrm{kcal} / \mathrm{kg})$ of male broilers from 22 to 42 days old. 
temperaturas acima de $29^{\circ} \mathrm{C}$, quando a ingestão de energia e de alimentos decresce em taxas mais rápidas.

Com os dados de CEM e GP obtidos neste estudo, pode-se inferir que a demanda de energia para ganho de peso reduziu à medida que a temperatura ambiente aumentou de 16 para $25^{\circ} \mathrm{C}$, o que poderia evidenciar uma possível redução na necessidade de mantença das aves à medida que a temperatura ambiente elevou. Esta hipótese foi fundamentada por Hurwitz et al. (1980), que verificaram que aves mantidas em temperaturas mais baixas exigem maior quantidade de energia para mantença, o que resulta em diminuição da energia disponível para produção.

Os tratamentos também influenciaram $(\mathrm{P}<0,01)$ a conversão alimentar (CA), que melhorou de forma quadrática até a temperatura estimada de $26,3^{\circ} \mathrm{C}$ (Figura 4). Essa melhora ocorrida entre as temperaturas de 16 e $25^{\circ} \mathrm{C}$ neste estudo corrobora os resultados obtidos por Smith \& Teeter (1987), em estudo com frangos de corte mantidos em ambientes frio $\left(7,2^{\circ} \mathrm{C}\right)$ e de conforto $\left(23,9^{\circ} \mathrm{C}\right)$. Por outro lado, a piora da CA observada entre as temperaturas de 25 e $32^{\circ} \mathrm{C}$ confirma os resultados obtidos por Hurwitz et al. (1980), Howlider \& Rose (1987) e Oliveira Neto et al. (2000), que também observaram efeito negativo da alta temperatura sobre a CA, e com a afirmativa de Bertechini et al. (1991) de que aves criadas sob altas temperaturas gastam mais energia para dissipar o excesso de calor corporal, apresentando resultados negativos na conversão alimentar.

A melhora gradativa na CA observada entre 16 e $25^{\circ} \mathrm{C}$ neste estudo confirma o relato anterior de aumento na eficiência de utilização de energia para ganho de peso das aves nesta faixa de temperatura.

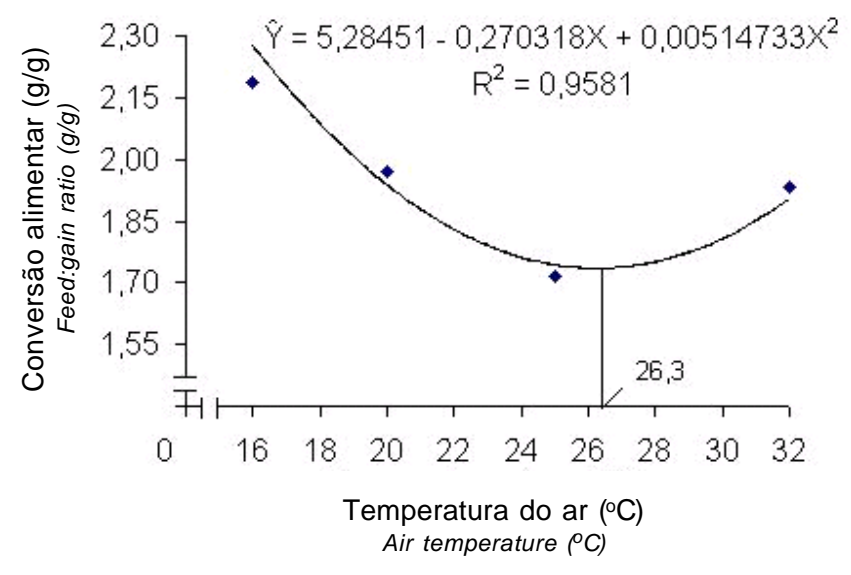

Figura 4 - Efeito da temperatura ambiente sobre a conversão alimentar de frangos de corte machos no período de 22 a 42 dias de idade.

Figure 4 - Effect of environmental temperature on feed:gain ratio of male broilers from 22 to 42 days old.
A redução no desempenho de aves sob influência do calor é atribuída principalmente à inabilidade da ave em eliminar o excesso de calor corporal (Donkoh \& Atuahene, 1988).

O peso absoluto ( $\mathrm{g}$ ) e os rendimentos $(\%)$ de peito, coxa e carcaça de frangos de corte aos 42 dias de idade mantidos em diferentes condições ambientais são apresentados na Tabela 3.

A temperatura ambiente influenciou $(\mathrm{P}<0,01)$ de forma quadrática o peso absoluto de carcaça, de modo que o maior valor foi obtido na temperatura estimada de $25,3^{\circ} \mathrm{C}$, segundo a equação: $Y=-893,748+210,345 X-4,15436 X^{2}\left(R^{2}=0,82\right)$. $\mathrm{O}$ peso absoluto da carcaça das aves mantidas em temperatura ambiente de $25^{\circ} \mathrm{C}$ foi 12,7 e $17,5 \%$ maior que o daquelas mantidas a 32 e $16^{\circ} \mathrm{C}$, respectivamente. No entanto, o rendimento de carcaça foi influenciado $(\mathrm{P}<0,01)$ de forma linear, aumentando com a elevação da temperatura ambiente, de acordo com a equação: $Y=72,3958+0,287956 \mathrm{X}$ $\left(\mathrm{r}^{2}=0,94\right)$, de modo semelhante ao verificado por Oliveira Neto et al. (2000).

Os resultados deste estudo permitem inferir que a variação no rendimento de carcaça foi conseqüência do maior peso de órgãos (Tabela 4) nas aves mantidas em ambiente frio $\left(16^{\circ} \mathrm{C}\right)$ e do menor peso nas aves mantidas sob alta temperatura $\left(32^{\circ} \mathrm{C}\right)$.

Observou-se efeito $(\mathrm{P}<0,01)$ da temperatura ambiente sobre o peso absoluto de peito, que variou de forma quadrática, apresentando valor máximo na temperatura estimada de $24,0^{\circ} \mathrm{C}$, segundo a equação: $\bar{Y}=-304,954+$ $68,5145 \mathrm{X}-1,42594 \mathrm{X}^{2}\left(\mathrm{R}^{2}=0,82\right)$, e o rendimento de peito dos frangos, que reduziu de forma linear $(\mathrm{P}<0,01)$, conforme a equação: $\bar{Y}=32,5555-1,34716 \mathrm{X}\left(\mathrm{r}^{2}=0,84\right)$.

$\mathrm{O}$ efeito negativo da alta temperatura $\left(32^{\circ} \mathrm{C}\right)$ sobre o peso absoluto de peito foi maior que o da baixa temperatura $\left(16^{\circ} \mathrm{C}\right)$. As reduções no peso absoluto do peito nas temperaturas de 32 e $16^{\circ} \mathrm{C}$ corresponderam a 20,3 e $14,3 \%$ em relação à observada na temperatura de $25^{\circ} \mathrm{C}$.

Efeito negativo da alta temperatura $\left(32^{\circ} \mathrm{C}\right)$ também foi observado sobre o rendimento de peito das aves, que reduziu $9,5 \%$ quando comparado ao das aves mantidas a $25^{\circ} \mathrm{C}$. Por outro lado, as aves mantidas sob baixa temperatura $\left(16^{\circ} \mathrm{C}\right)$ apresentaram rendimento de peito $4,1 \%$ maior que o daquelas mantidas a $25^{\circ} \mathrm{C}$, cujo valor foi similar ao das aves mantidas a $20^{\circ} \mathrm{C}$. Efeito negativo da alta temperatura sobre o peso absoluto e o rendimento de peito das aves também foi verificado por Alleman \& Leclerk (1997) e Oliveira Neto et al. (2000).

Quanto ao rendimento de peito das aves mantidas à baixa temperatura $\left(16^{\circ} \mathrm{C}\right)$, o resultado obtido neste estudo foi similar ao encontrado por Rose \& Michie (1987), em 
Tabela 3 - Peso absoluto (g) e rendimento (\%) de carcaça e de cortes nobres de frangos de corte aos 42 dias de idade mantidos sob diferentes temperaturas ambiente

Table 3 - Results of absolute weight ( $g$ ) and of carcass and prime cuts yield (\%) of male broilers at 42 days old on different environmental temperatures

\begin{tabular}{|c|c|c|c|c|c|}
\hline \multirow[t]{2}{*}{$\begin{array}{l}\text { Parâmetro } \\
\text { Parameter }\end{array}$} & \multicolumn{4}{|c|}{$\begin{array}{c}\text { Temperatura do ambiente }\left({ }^{\circ} \mathrm{C}\right) \\
\text { Air temperature }\end{array}$} & \multirow[b]{2}{*}{ CV (\%) } \\
\hline & 16 & 20 & 25 & 32 & \\
\hline & \multicolumn{4}{|c|}{$\begin{array}{l}\text { Peso absoluto }(\mathrm{g}) \\
\text { Absolute weight }\end{array}$} & \\
\hline Carcaça (Carcass) $)^{1}$ & 1.476 & 1.627 & 1.789 & 1.561 & 7,23 \\
\hline Peito (Breast) ${ }^{1}$ & 448 & 483 & 523 & 417 & 8,80 \\
\hline \multirow[t]{3}{*}{ Coxa $(\text { Thigh })^{1}$} & 185 & 203 & 227 & 206 & 8,09 \\
\hline & \multicolumn{4}{|c|}{ Rendimento (\%) } & \\
\hline & \multicolumn{4}{|c|}{ Yield } & \\
\hline Carcaça (Carcass) $)^{3}$ & 77,9 & 77,9 & 79,7 & 81,7 & 2,16 \\
\hline Peito $(\text { Breast) })^{3}$ & 30,6 & 29,8 & 29,4 & 26,6 & 5,25 \\
\hline Coxa $(\text { Thigh })^{2}$ & 12,6 & 12,6 & 12,6 & 13,2 & 5,26 \\
\hline
\end{tabular}

1,2 Efeito quadrático $(P<0,01)$ e $(P<0,03)$, respectivamente.

1,2 Quadratic effect $(P<0.01)$ and $(P<0.03)$, respectively.

3 Efeito linear $(P<0,01)$ (Linear effect, $P<0.01)$.

estudo conduzido com patos, no qual o rendimento de peito foi, numericamente, maior aos $14^{\circ} \mathrm{C}(23,3 \%)$ que aos $23^{\circ} \mathrm{C}(22,9 \%)$.

A temperatura ambiente também influenciou o peso absoluto $(\mathrm{P}<0,01)$ de coxa das aves, que aumentou até a temperatura de $26,3^{\circ} \mathrm{C}$, estimada pela equação: $\mathrm{Y}=-93,922$ $+24,2172 \mathrm{X}-0,460574 \mathrm{X}^{2}\left(\mathrm{R}^{2}=0,81\right)$ e o rendimento $(\mathrm{P}<0,03)$ de coxa, que reduziu de forma quadrática até a temperatura estimada de $19,4^{\circ} \mathrm{C}$ (Figura 5). Enquanto o peso absoluto de coxa apresentou variação similar à verificada para o peso absoluto de peito, o resultado de rendimento de coxa obtido na alta temperatura $\left(32^{\circ} \mathrm{C}\right)$ diferiu do observado para o rendimento de peito, tendo aumentado $4,8 \%$ em relação ao das aves mantidas a $25^{\circ} \mathrm{C}$. Resultado semelhante foi relatado por Oliveira Neto et al. (2000), que também verificaram efeito positivo da alta temperatura sobre o rendimento de coxa de frangos de corte.

Com os resultados de peso absoluto e de rendimento de peito e coxa, ficou evidenciada possível influência da alta temperatura no metabolismo de proteína, de modo que a deposição deste nutriente no tecido muscular da coxa revelou-se prioritária à do músculo de peito dos frangos. Este crescimento muscular diferenciado atribuído à alta temperatura pode estar relacionado às características das fibras musculares, que, no caso de peito, são predominantemente brancas, com menor demanda de irrigação sangüínea, e no da coxa, são predominantemente vermelhas e, portanto, mais irrigadas.

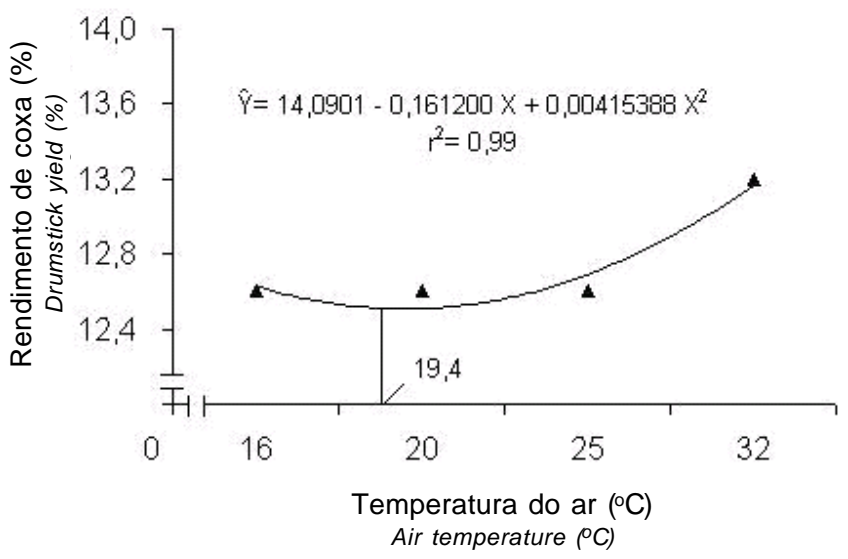

Figura 5 - Efeito da temperatura ambiente sobre o rendimento de coxa (\%) de frangos de corte machos no período de 22 aos 42 dias de idade.

Figure 5 - Effect of environmental temperature on carcass yield (\%) of male broilers from 22 to 42 days old.

Segundo Baziz et al. (1996), a influência da alta temperatura ambiente sobre os músculos do peito e das pernas pode estar relacionada às características energéticas e aos respectivos substratos, glicose e ácidos graxos, além das modificações no metabolismo protéico (síntese e degradação), o qual pode explicar a diferença no ganho de proteína muscular e no desenvolvimento do músculo (Temim et al., 1999).

Os pesos absoluto (g) e relativo (\%) dos órgãos (coração, fígado, moela e proventrículo) das aves mantidas em diferentes temperaturas ambientais encontram-se na Tabela 4.

A temperatura ambiente influenciou de forma quadrática os pesos absolutos do coração e do fígado $(\mathrm{P}<0,01)$, que diminuíram a partir das temperaturas de 19,7 e $19,5^{\circ} \mathrm{C}$, estimadas respectivamente, pelas equações: $\bar{Y}=-1,19472$ $+1,56147 \mathrm{X}-0,0395636 \mathrm{X}^{2}\left(\mathrm{R}^{2}=0,99\right)$ e $\quad \mathrm{Y}=18,1007+$ $2,38086 X-0,0609782 X^{2}\left(R^{2}=0,99\right)$. No entanto, os pesos relativos do coração e do fígado diminuíram de forma linear $(\mathrm{P}<0,01)$ com o aumento de 16 para $32^{\circ} \mathrm{C}$ na temperatura ambiente, conforme as equações, respectivamente: $\bar{Y}=1,40154-0,0267758 \mathrm{X}\left(\mathrm{r}^{2}=0,94\right)$ e $\bar{Y}=3,42724-0,0440106 \mathrm{X}$ $\left(\mathrm{r}^{2}=0,92\right)$.

A temperatura ambiente também influenciou $(\mathrm{P}<0,01)$ de forma quadrática os pesos absoluto e relativo da moela, sendo que o peso absoluto aumentou até a temperatura de $23,9^{\circ} \mathrm{C}$ e o relativo reduziu até a temperatura de $30^{\circ} \mathrm{C}$, estimadas, respectivamente, pelas equações: $\bar{Y}=-0,0648422+$ $2,29366 \mathrm{X}-0,0480342 \mathrm{X}^{2}\left(\mathrm{R}^{2}=0,68\right)$ e $\mathrm{Y}=2,17504-0,0443223 \mathrm{X}$ $+0,00073409 X^{2}\left(R^{2}=0,99\right)$.

Não se verificou efeito $(\mathrm{P}>0,05)$ dos tratamentos sobre os pesos absoluto e relativo do proventrículo. Esta diferença 
Tabela 4 - Pesos absoluto (g) e relativo (\%) de órgãos de frangos de corte aos 42 dias de idade mantidos sob diferentes temperaturas ambiente

Table 4 - Results of absolute $(g)$ and relative (\%) weights of organs of male broilers at 42 days old on different environmental temperatures

\begin{tabular}{|c|c|c|c|c|c|}
\hline \multirow[t]{2}{*}{$\begin{array}{l}\text { Parâmetro } \\
\text { Parameter }\end{array}$} & \multicolumn{4}{|c|}{$\begin{array}{c}\text { Temperatura do ar }\left({ }^{\circ} \mathrm{C}\right) \\
\text { Air temperature }\end{array}$} & \multirow[b]{2}{*}{$\mathrm{CV}(\%)$} \\
\hline & 16 & 20 & 25 & 32 & \\
\hline & \multicolumn{4}{|c|}{$\begin{array}{l}\text { Peso absoluto }(\mathrm{g}) \\
\text { Absolute weight }\end{array}$} & \\
\hline Coraçãão $^{1}$ & 13,7 & 14,2 & 13,1 & 8,3 & 11,69 \\
\hline $\begin{array}{l}\text { Heart } \\
\text { Fígado }{ }^{1} \\
\text { Liver }\end{array}$ & 39,9 & 42,4 & 39,7 & 32,1 & 11,66 \\
\hline Moela $^{1}$ & 25,0 & 25,1 & 26,4 & 23,4 & 12,42 \\
\hline $\begin{array}{l}\text { Gizzard } \\
\text { Proventrículo }\end{array}$ & 7,6 & 7,4 & 7,8 & 6,9 & 15,75 \\
\hline \multicolumn{6}{|l|}{ Proventriculus } \\
\hline \multicolumn{6}{|c|}{$\begin{array}{c}\text { Rendimento }(\%) \\
\text { Yield }\end{array}$} \\
\hline Coração ${ }^{2}$ & 0,92 & 0,88 & 0,73 & 0,53 & 12,27 \\
\hline $\begin{array}{l}\text { Heart } \\
\text { Fígado }^{2}\end{array}$ & 2,66 & 2,63 & 2,22 & 2,04 & 10,78 \\
\hline $\begin{array}{l}\text { Liver } \\
\text { Moela } \\
\text { Gizzard }\end{array}$ & 1,71 & 1,56 & 1,48 & 1,52 & 13,01 \\
\hline $\begin{array}{l}\text { Proventrículo } \\
\text { Proventriculus }\end{array}$ & 0,51 & 0,47 & 0,44 & 0,45 & 16,78 \\
\hline
\end{tabular}

Tabela 5 - Valores médios de temperatura retal, de crista, de peito e de perna de frangos de corte aos 42 dias de idade mantidos sob diferentes temperaturas ambiente

Table 5 - Average values of rectal temperature and temperatures of crest, breast and leg of male broilers at 42 days old on different environmental temperatures

\begin{tabular}{|c|c|c|c|c|c|}
\hline \multirow[t]{2}{*}{$\begin{array}{l}\text { Parâmetro } \\
\text { Parameter }\end{array}$} & \multicolumn{4}{|c|}{$\begin{array}{c}\text { Temperatura do ar }\left({ }^{\circ} \mathrm{C}\right) \\
\text { Air temperature }\end{array}$} & \multirow[b]{2}{*}{$\mathrm{CV}(\%)$} \\
\hline & 16 & 20 & 25 & 32 & \\
\hline $\begin{array}{l}\text { Temperatura retal } \\
\text { Rectal temperature }\end{array}$ & 40,9 & 41,0 & 42,3 & 42,1 & 8,82 \\
\hline Temperatura de crista $^{1}$ & 33,1 & 36,0 & 37,1 & 39,9 & 1,89 \\
\hline $\begin{array}{l}\text { Crest temperature } \\
\text { Temperatura de peito }{ }^{1} \\
\text { Breast temperature }\end{array}$ & 36,7 & 38,4 & 39,7 & 41,0 & 1,28 \\
\hline $\begin{array}{l}\text { Temperatura de perna } \\
\text { Leg temperature }\end{array}$ & 36,7 & 38,5 & 39,4 & 40,7 & 1,15 \\
\hline
\end{tabular}

na variação de peso relativo dos órgãos avaliados, com exceção do proventrículo, ocorrida entre os ambientes de baixa $\left(16^{\circ} \mathrm{C}\right)$ e alta $\left(32^{\circ} \mathrm{C}\right)$ temperatura, constitui um ajuste fisiológico das aves ao estresse por frio e calor. Enquanto no frio o aumento do peso relativo dos órgãos está associado à necessidade de maior produção de calor corporal, a redução do tamanho relativo destes órgãos, no ambiente de alta temperatura, corresponde à tentativa da ave de reduzir a produção de calor interno.

A redução dos pesos dos órgãos de aves expostas a altas temperaturas também foi observada por Balnave (1972) e Oliveira Neto et al. (2000), enquanto o aumento, em condições de baixa temperatura, foi constatado também por Valerio et al. (2000).

Com base nos resultados de peso relativo de órgãos, pode-se inferir que a modificação dos pesos verificada nos diferentes ambientes ocorreu em função dos efeitos da temperatura ambiente (frio e calor) sobre os parâmetros fisiológicos e hormonais das aves, e não sobre o consumo de ração.

Considerando a influência que órgãos metabolicamente ativos, como fígado e coração, têm sobre a produção de calor e, conseqüentemente, sobre o gasto de energia dos frangos, pode-se deduzir que a exigência de mantença das aves expostas ao calor é menor que a das aves expostas ao frio. Esta hipótese estaria fundamentada nos resultados de Yahav et al. (1998), que associaram a redução na exigência de mantença das aves à diminuição da massa de órgãos.

Quanto aos parâmetros fisiológicos (Tabela 5), constatou-se que a temperatura ambiente influenciou $(\mathrm{P}<0,01)$ as temperaturas de crista, peito e perna, que aumentaram de forma linear, respectivamente, segundo as equações: $\bar{Y}=27,8056+0,379623 \mathrm{X}\left(\mathrm{r}^{2}=0,96\right) ; \mathrm{Y}=33,2136+0,249049 \mathrm{X}$ $\left(r^{2}=0,99\right)$ e $Y=33,8672+0,216906 X\left(r^{2}=0,98\right)$. O ambiente térmico não influenciou a temperatura retal.

Considerando que a temperatura corporal de frangos de corte adultos varia entre 41 e $42^{\circ} \mathrm{C}$ (Macari et al., 1994), pode-se inferir, com bases nos dados obtidos, que as aves foram eficientes em dissipar o calor corporal pelos meios sensíveis. Isso ficou caracterizado pela variação nas temperaturas de crista, peito e perna e pela constância na temperatura retal das aves entre os ambientes. Segundo Macari et al. (1994), as variações de temperatura na periferia (patas, cristas e asas) ocorrem pela tentativa da ave de manter a constância da temperatura corporal.

Foi observado, neste estudo, que a temperatura de crista, peito e perna variou em uma relação inversa à dos pesos relativos dos órgãos, o que estaria coerente com a necessidade de produção ou perda de calor, tendo em vista o envolvimento destes parâmetros na manutenção da homeotermia do corpo das aves.

\section{Conclusões}

Os melhores resultados de ganho de peso e de pesos absolutos de peito, coxa e carcaça de frangos de corte 
machos da linhagem Avian Farms foram obtidos nas aves criadas em temperatura ambiente de 24 a $26,3^{\circ} \mathrm{C}$.

Temperaturas ambientes abaixo de $24^{\circ} \mathrm{C}$ e acima de $26,3^{\circ} \mathrm{C}$ influenciaram negativamente o ganho de peso e os pesos absolutos de peito, coxa e carcaça.

Os processos termorregulatórios associados à redução no peso dos órgãos metabolicamente ativos das aves constituíram-se ajustes eficientes para manutenção da homeotermia quando a temperatura ambiente aumentou de 16 para $32^{\circ} \mathrm{C}$.

\section{Literatura Citada}

ALLEMAN, F.; LECLERCQ, B. Effects of dietary protein and environmental temperature on growth performance and water consumption of male broiler chickens. British of Poultry Science, v.38, p.607-610, 1997.

BAÊTA, F.C.; SOUZA, C.F. Ambiência em edificações rurais: conforto animal. Viçosa, MG: Universidade Federal de Viçosa, 1998. p. 246.

BALDWIN, R.L.; SMITH, N.E.; TAYLOR, J. et al. Manipulating metabolic parameters to improve growth rate and milk secretion. Journal of Animal Science, v.51, p.1416-1428, 1980.

BALNAVE, D. The effect of temperature and length of exposure on liver composition and hepatic lipogenic enzyme activity in the immature male chick (Gallus domesticus). Compendium of Biochemistry and Physiology, v.43, p.999-1007, 1972.

BAZIZ, H.A.; GERAERT, P.A.; PADILHA, C.F. et al. Chronic heat exposure enhance fat deposition and modifies muscles and fat partition in broiler carcasses. Poultry Science, v.75, p.505513, 1996.

BERTECHINI, A.G.; ROSTAGNO, H.S.; SILVA, M.A. et al. Efeito da temperatura ambiente e nível de energia da ração sobre o desempenho e a carcaça de frangos de corte. Revista da Sociedade Brasileira de Zootecnia, v.20, p.218-228, 1991.

CHARLES, D.R.; GROOM, C.M.; BRAY, T.S. The effects of temperature on broilers: interactions between temperature and feeding regime. British Poultry Science, v.22, p.475-481, 1981.

CHENG, T.K.; HAMRE, M.L.; COON, C.N. Effect of environmental temperature, dietary protein, and energy on broiler performance. Journal Applied of Poultry Science, v.6, p.1-17, 1997.

COOPER, M.A.; WASHBURN, K.W. The relationships of body temperature to weight gain, feed consumption, and feed utilization in broilers under heat stress. Poultry Science, v.77, p.237-242, 1998.

CURTIS, S.E. Environmental management in animal agriculture . Ames: The Iowa State University, 1983. p.409.

DEATON, J.W.; REECE, F.N.; McNAUGHTON, J.L. The effect of temperature during the growing period on broiler performance. Poultry Science, v.57, p.1070-1074, 1978.

DONKOH, A.; ATUAHENE, C.C. Management of environmental temperature and rations for poultry production in the hot and humid tropics. International Journal of Biometeorology, v.32, p.247-253, 1988 .
HOWLIDER, M.A.R; ROSE, S.P. Temperature and growth of broiler. World Poultry Science, v.43, p.228-237, 1987.

HURWITZ, S.; WEISLBERG, M.; EISNER, U. et al. The energy requirements and performance of growing chickens and turkeys as affected by environmental temperature. Poultry Science, v.59, p. 2290-2299, 1980.

LANA, G.R.Q.; ROSTAGNO, H.S.; ALBINO, L.F.T. et al. Efeito da temperatura ambiente e da restrição alimentar sobre o desempenho e a composição de carcaça de frangos de corte. Revista Brasileira de Zootecnia, v.24, p.1117-1123, 2000.

MACARI, M.; FURLAN, L.F.; GONZALES, E. Fisiologia aviária aplicada a frangos de corte. São Paulo: FUNEP/ UNESP, 1994. 296p.

Mc DOWELL, R.E. Bases biológicas de la producción animal en zonas tropicales. Zaragoza: Acribia, 1974. p.692.

OLIVEIRA NETO, A.R.; OLIVEIRA, R.F.M.; DONZELE, J.L et al. Efeito da temperatura ambiente sobre o desempenho e características de carcaça de frangos de corte alimentados com dietas controlada e dois níveis de energia metabolizável. Revista Brasileira de Zootecnia, v.29, p.183-190, 2000.

PERRAULT, N.; LEESON, S. Effect of environmental temperature, dietary energy, and feeding level on growth and carcass composition of male broiler chickens to 35 days of age. Canadian Journal of Animal Science, v.72, p.695-702, 1992.

ROSE, K.R.; MICHIE, W. Environmental temperature and dietary protein concentration for growing turkeys. Poultry Science, v.28, p.213-218, 1987.

ROSTAGNO, H.S.; BARBARINO JR., P.; BARBOZA, W.A. Exigências nutricionais das aves determinadas no Brasil. In: SIMPÓSIO INTERNACIONAL SOBRE EXIGÊNCIAS NUTRICIONAIS DE AVES E SUÍNOS, 1996, Viçosa, MG. Anais... Viçosa, MG: Universidade Federal de Viçosa, 1996. p.361.

SELL, J.L. Use of supplemental fat to improve productive efficiency of poultry. In: FLORIDA NUTRITION CONFERENCE, 1979, Florida. Proceedings... Florida: 1979. p.43.

SMITH, M.O.; TEETER, R.G. Influence of feed intake and ambient temperature stress on the relative yield of broilers parts. Nutritional Report International, v.35, p.299-306, 1987.

TEMIM, S.; CHAGNEAU, A.M.; GUILLAUMMIN, S. et al. Effect of chronic heat exposure and protein intake on growth performance, nitrogen retention and muscle development in broiler chickens. Reproduction Nutrition Development, v.39, p.145-156, 1999.

UNIVERSIDADE FEDERAL DE VIÇOSA - UFV. Central de Processamento de Dados - UFV - CPD. SAEG - Sistema para análise estatística e genética. Viçosa, MG, 1997. p.59.

VALERIO, S.R.; OLIVEIRA, R.F.M.; DONZELE, J.L. et al. Efeito dos níveis de lisina digestível sobre as vísceras de frangos de corte de 1 a 21 dias de idade, mantidas em diferentes temperaturas. In: REUNIÃO ANUAL DA SOCIEDADE BRASILEIRA DE ZOOTECNIA, 37., 2000, Viçosa, MG. Anais... Viçosa, MG: Sociedade Brasileira de Zootecnia, 2000. p. 284.

YAHAV, S.; LUGER, D.; CAHANER, A. et al. Thermoregulation in naked neck chickens subjected to different ambient temperatures. British Poultry Science, v.39, p.133-138, 1998. 